\section{Relationships of Seed Size and Shape with Polyembryony and the Zygotic or Nucellar Origin of Citrus spp. Seedlings}

\author{
Kim D. Bowman \\ U.S. Department of Agriculture, Agricultural Research Service, U.S. \\ Horticultural Research Laboratory, 2120 Camden Road, Orlando, FL 32803 \\ Frederick G. Gmitter, Jr. \\ University of Florida, Institute of Food and Agricultural Sciences, Citrus \\ Research and Education Center, 700 Experiment Station Road, Lake Alfred, \\ FL 33850
}

\section{Xulan Hu \\ Yunnan Agricultural Extension Center, 3 Jiao Lin Road, West Station, Kunming, Yunnan, People's Republic of China \\ Additional index words. Smooth Flat Seville, Yuma, Cipo, isozyme, xenia}

\begin{abstract}
We examined the relationship between seed size and shape in Citrus and the number and type of seedlings produced by individual seeds for each of three citrus cultivars. Seed size and shape were related to the number of seedlings produced and the likelihood of recovering a zygotic seedling. The relationship between seed size and shape and the likelihood of recovering a zygotic seedling most often was connected with weight and thickness of a seed. This relationship might be of sufficient strength to use in some aspects of cultivar development. However, the relationship did not appear strong enough to be of practical value for application in commercial production of purely nucellar rootstock seedlings.
\end{abstract}

Many citrus selections and relatives yield seedlings that are derived from nucellar tissue and usually are genetically identical to the seed source tree. The tendency for production of nucellar seedlings differs greatly among citrus species (Hodgson, 1967). Hutchison (1985) proposed that control of this trait involves multiple genes with complex dominance, although in some specific crosses the inheritance patterns appear relatively simple (Parlevliet and Cameron, 1959). The natural generation of clones by nucellar embryony in citrus has been used effectively for the economical production of commercial rootstocks. However, this characteristic also has presented difficulties in citrus breeding. Many selections that could be used as parents exhibit extensive nucellar embryony and only rarely yield hybrid seed. The resulting problems become especially pronounced in rootstock breeding, where nucellar embryony is undesirable in the seed parent (because hybrids are sought) but is desired among progeny (for economy of commercial rootstock production).

The ability to separate the seed that will produce nucellar seedlings from those that will produce zygotic seedlings before planting by grading or sorting could benefit commer-

Received for publication 26 Sept. 1994. Accepted for publication 26 May 1995. The cost of publishing this paper was defrayed in part by the payment of page charges. Under postal regulations, this paper therefore must be hereby marked advertisement solely to indicate this fact. cial citrus production and citrus breeding programs. Eliminating rootstock seed that yields zygotics before planting would save the time and the nursery resources now invested in growing off-type seedlings that eventually must be removed by roguing and could reduce the number of off-type plants that often escape roguing. In breeding, eliminating nucellaronly seed from controlled crosses before planting would have a similarly favorable effect.

Citrus seed size has been studied in relation to ploidy (Esen and Soost, 1973; Starrantino and Reforgiato-Recupero, 1981), germination (Chilembwe et al., 1992), and the probability of obtaining a zygotic seedling (Xiang and Roose, 1988). Our study more thoroughly investigated the relationship between seed size and shape and the zygotic or nucellar origin of the subsequent seedlings.

Our objective was to determine whether the size or shape of individual seeds could be used to predict the type (nucellar or zygotic) of seedlings obtained from that seed. The number of seedlings derived from each seed also was examined because polyembryony is another factor that may affect seed shape in citrus and complicate attempts to discriminate seed that will produce nucellar seedlings from those that yield zygotic seedlings.

\section{Materials and Methods}

Two rootstock cultivars and one sweet orange clone were selected for use in this study. Smooth Flat Seville (Citrus spp. hybrid of uncertain origin, see Barrett and Rhodes,
1976) and Yuma [Poncirus trifoliata (L.) Raf. $\times$ Citrus sp. hybrid of uncertain origin] are citrus rootstock cultivars with frequencies of zygotic plants higher than normally can be tolerated in commercial nursery production. These two cultivars are reported to have some promise for use in Florida (Castle et al., 1992; Grimm and Garnsey, 1968; Hutchison et al., 1992), but neither has been used widely, in part because of the frequent off-types in seedling populations. 'Cipo' sweet orange has been used recently in citrus breeding because it transmits a unique procumbent growth habit to hybrid progeny (Bowman, 1994a, 1994b). However, 'Cipo' seed only rarely produce an embryo of zygotic origin; most of its seedlings are nucellar.

Controlled crosses were made on 'Cipo' sweet orange (CRC 3896) at the Univ. of California Citrus Variety Collection, Riverside, during Spring 1992. Seeds were harvested in Fall 1992 from these crosses, openpollinated 'Cipo' at Riverside, and three openpollinated cultivars at the Whitmore Foundation Farm near Leesburg, Fla.: 'Cipo' sweet orange (accession no. 77-155-1; probably identical to CRC 3896), Smooth Flat Seville (AHW93-177), and Yuma (AF-60-1). All of the seed obtained from the controlled crosses were used for the experiment ( 225 seeds from 'Cipo' $\mathrm{x}$ Poncirus trifoliata and 93 seeds from 'Cipo' $x$ Citrus ichangensis Swing.). Seed from openpollination were extracted from a random sample of fruit. All seed collected from Riverside and the seed from open-pollinated 'Cipo' in Florida were washed, treated with 8hydroxyquinolinol sulfate, dried for several hours, and stored at $5 \mathrm{C}$ (or on ice for transport) until the beginning of the pectinase treatment. Smooth Flat Seville and Yuma seed were extracted from fruit and washed in water just before pectinase treatment.

All groups of seed were soaked overnight in a pectinase solution ( $7.5 \mathrm{~g}$ pectinase $/ 1$ liter water) at room temperature $(\approx 21 \mathrm{C})$, drained, rinsed with water, and dried at $\approx 21 \mathrm{C}$ for 3.5 to $8 \mathrm{~h}$. After these steps, each seed was individually identified, weighed, and measured (Fig. 1). All seed were planted in individual pot cells using a soilless potting mix. Seedlings were cultured in a warm greenhouse until ready for seedling count and type determinations. The number of seedlings per seed was determined by counting the number of independently rooted shoots that emerged from the soil and grew to sufficient size (generally about two leaves) for leaf sampling and isozyme determination. Seedling origin was determined to be either nucellar or zygotic by analysis of isozymes from leaf sap using horizontal starch gel electrophoresis (Soost et al., 1980). Leaf samples were collected 3 to 13 months after planting seed. Isozyme stains were used as described by Vallejos (1983) and included phosphoglucose isomerase (PGI, E.C.5.3.1.9), phosphoglucomutase(PGM, E.C.2.7.5.1), peroxidase (PER, E.C.1.11.1.7), and 6phosphogluconate dehydrogenase (PGD, E.C.1.1.1.44); a total of five isozyme loci were assayed. Seedlings were considered nucellar if all alleles observed (using at least three of 
the staining systems) were identical to the seed parent tree (Table 1). Seedlings were considered zygotic if any changes in banding patterns were evident. Genetic interpretation of banding patterns for PGD are not completely understood in citrus, but changes in banding patterns can be interpreted to indicate zygotic origin of seedlings (Durham et al., 1992). Smooth Flat Seville and Yuma appear to be heterozygous for each of two distinct loci detected by the PGD stain. Questionable isozyme results were repeated until identity was verified. The accuracy of the isozyme method increases with an increase in the number of loci examined and varies according to the isozyme alleles present in the seed parent and the potential pollen parent. Based on the likelihood that most zygotic seedlings arose from self-pollination, we estimated that the accuracy in this study ranged from $75 \%$ for 'Cipo' (with two heterozygous loci) to 96.9\% for Smooth Flat Seville (with five heterozygous loci). An additional 100 seeds from each cultivar were collected from the trees at the Whitmore Foundation Farm during the 199394 fruit season. Seed was dissected and visually classified as monoembryonic or polyembryonic. All data were analyzed by SAS software (SAS Institue, Cary, N.C.) using logistic regression with 1) the full model (all seed measurement variables included) for prelimi-

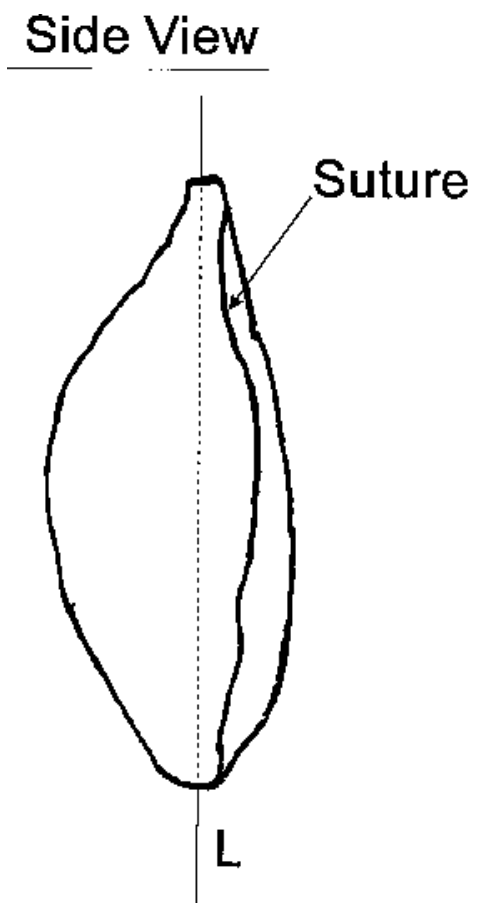

\section{Cross Section View}

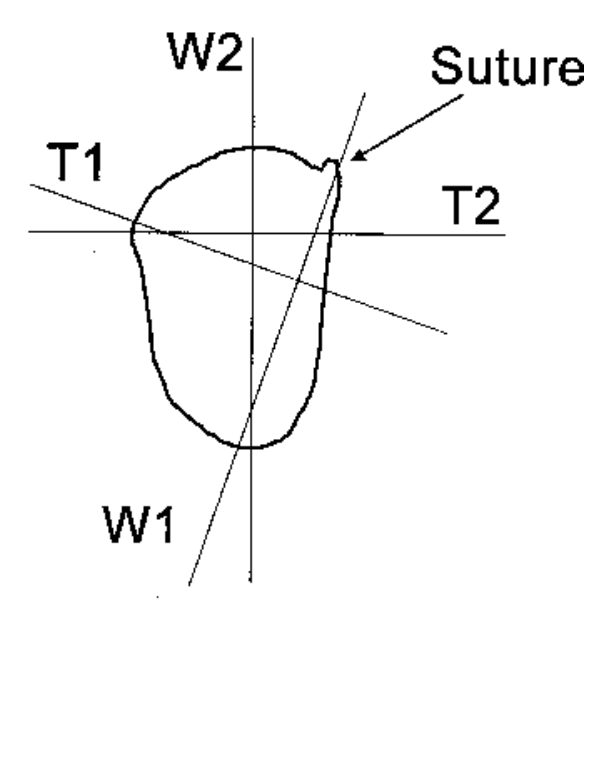

Fig. 1. Seed size and shape measurements.

W Weight (milligram)

L Length (millimeter)

W1 Width 1 (milligram)

T1 Thickness 1 (millimeter)

W2 Width 2 (millimeter)

T2 Thickness 2 (millimeter)

nary analysis and 2) the stepwise model selection procedure for calculation of the logit equation.

\section{Results and Discussion}

The SD of seed sizes and shapes were large for each of the three cultivars (Table 2). The number of seedlings produced from each seed varied from zero (no germination) to four (Table 3); the most frequent number of seedlings produced was one. Logistic regression showed that the number of seedlings was related to some of the seed dimensions, which supports the previously reported relationship between seed size and number of embryos (Chilembwe et al., 1992). However, handling multiple seedlings only is a problem when nucellar and zygotic seedlings are produced in mixed populations. There is little practical value to a relationship between seed size and number of seedlings, so this subject was not examined in more detail.

The percentage of seed with multiple embryos is frequently used as an indicator of a cultivar's tendency to produce nucellar seedlings. A high percentage of polyembryonic seed would be interpreted as an indication that the cultivar will yield mostly nucellar seedlings and few hybrids (Hutchison, 1985). 'Cipo' produced polyembryonic seed much more fre- 


\begin{tabular}{|c|c|c|c|c|c|c|c|c|c|c|c|c|c|c|}
\hline \multirow{3}{*}{$\begin{array}{l}\text { Seed } \\
\text { cultivar }\end{array}$} & \multirow{3}{*}{$\begin{array}{c}\text { Seed } \\
\text { location }^{y}\end{array}$} & \multirow{3}{*}{$\begin{array}{l}\text { Pollen } \\
\text { source }\end{array}$} & \multicolumn{12}{|c|}{ Avg dimensions $^{\mathrm{z}}$} \\
\hline & & & \multicolumn{6}{|c|}{ Mean } & \multicolumn{6}{|c|}{$\mathrm{SD}$} \\
\hline & & & $\mathrm{W}$ & $\mathrm{L}$ & W1 & $\mathrm{T} 1$ & W2 & $\overline{\mathrm{T} 2}$ & $\mathrm{~W}$ & $\mathrm{~L}$ & W1 & $\mathrm{T} 1$ & W2 & $\mathrm{T} 2$ \\
\hline Smooth Flat Seville & $\mathrm{F}$ & Open & 211 & 14.72 & 5.25 & 7.14 & 7.27 & 4.95 & 57.6 & 1.96 & 0.78 & 1.14 & 1.05 & 0.76 \\
\hline Yuma & $\mathrm{F}$ & Open & 136 & 11.16 & 4.33 & 5.81 & 6.01 & 3.92 & 75.6 & 1.75 & 1.13 & 1.38 & 1.32 & 0.96 \\
\hline \multirow[t]{4}{*}{ Cipo } & $\mathrm{F}$ & Open & 189 & 14.01 & 5.22 & 6.57 & 6.69 & 4.81 & 81.1 & 2.19 & 3.72 & 1.53 & 1.46 & 1.35 \\
\hline & $\mathrm{R}$ & Open & 136 & 13.07 & 4.75 & 6.03 & 6.13 & 4.35 & 42.0 & 1.59 & 0.78 & 1.03 & 1.00 & 0.94 \\
\hline & $\mathrm{R}$ & trifoliata & 107 & 12.42 & 3.99 & 5.57 & 5.72 & 3.66 & 64.1 & 2.02 & 1.31 & 1.30 & 1.21 & 1.42 \\
\hline & $\mathrm{R}$ & ichangensis & 173 & 13.62 & 4.93 & 6.70 & 6.91 & 4.63 & 72.6 & 1.85 & 1.14 & 1.51 & 1.30 & 1.17 \\
\hline
\end{tabular}

${ }^{\mathrm{z}}$ See Fig. 1 for information on acronyms.

${ }^{y} \mathrm{~F}=$ Whitmore Foundation Farm, Leesburg, Fla.; R = Citrus Variety Collection, Univ. of California, Riverside.

(using only the seed variables selected by the stepwise procedure) were calculated for Smooth Flat Seville and Yuma (Table 5). Variables that were not chosen by the stepwise procedure with a significance for entry of 0.20 and a significance level for staying of 0.10 are not included in the logit equations.

The percentage of Smooth Flat Seville seed in the entire population that only yielded nucellar seedlings was $46.6 \%$ (129 of 277 germinated seed). Using the calculated logit equation (Table 5), the probability that the seedlings would be nucellar only could be predicted for each Smooth Flat Seville seed on the basis of three seed variables (weight, length, and thickness) and a subset of seeds could be selected containing a larger percentage of seeds that would yield only nucellar seedlings. The proportion of actual nucellar seedlings in the predicted population (and the total number of seed predicted to be nucellar) could be shifted by the logit probability level that was chosen. For example, the percentage of seed yielding only nucellar seedlings in the predicted nucellar seedling population was $58 \%$ at $P \geq 0.50$ (65 actual nucellar seedlings of 112 predicted nucellar seedlings). The percentage of nucellar seedlings increased gradually to $100 \%$ at $P$ $\geq 0.72$ (two actual nucellars of two predicted nucellars). The logit probability level that was needed to surpass $85 \%$ purity in the predicted nucellar population was $P \geq 0.68$ (12 actual nucellars of 14 predicted nucellars). As the weight of a Smooth Flat Seville seed increased, the probability decreased that the seed would yield only nucellar seedlings, but as the length and thickness (T2) of the seed increased, the probability increased that the seed would yield only nucellar seedlings.

For the entire population from Yuma, the percentage of seed only yielding nucellar seedlings was $69.7 \%$ (131 pure nucellars of 188 germinated seed). Using the calculated logit equation for Yuma to select seed, the percentage of seed yielding only nucellar seedlings in the predicted nucellar seedling population was $70.9 \%$ at $P \geq 0.50$ (127 actual nucellar seedlings of 179 predicted nucellar seedlings). The percentage of nucellar seedlings increased gradually to $78.6 \%$ at $P \geq 0.74$ (55 actual nucellars of 70 predicted nucellars). As the logit probability level increased to $>0.74$, the percentage of actual nucellars in the predicted population decreased. As W1 of a Yuma seed increased, the probability increased that a seed would be nucellar only; however, as W2 of a seed increased, the probability decreased that a seed would be nucellar only. There was an

Table 3. Percentages of polyembryonic seed based on embryo counts (1993 season) and seedlings recovered (1992 season). ${ }^{2}$

\begin{tabular}{|c|c|c|c|c|c|c|}
\hline \multirow{2}{*}{$\begin{array}{l}\text { Seed } \\
\text { cultivar }\end{array}$} & \multirow{2}{*}{$\begin{array}{c}\text { Polyembryonic } \\
\text { seed } \\
(\%)^{\mathrm{x}}\end{array}$} & \multicolumn{5}{|c|}{$\begin{array}{c}\text { Seed yielding } \\
\text { each no. seedlings } \\
(\%)^{\mathrm{y}}\end{array}$} \\
\hline & & 0 & 1 & 2 & 3 & 4 \\
\hline Smooth Flat Seville & 29 & 7.7 & 68.3 & 22.7 & 1.3 & 0 \\
\hline Yuma & 31 & 36.7 & 59.3 & 4.0 & 0 & 0 \\
\hline Cipo & 98 & 17.5 & 49.7 & 28.8 & 3.6 & 0.3 \\
\hline
\end{tabular}

${ }^{\mathrm{z}}$ All open-pollinated.

y 1992 Season.

x1993 Season.

Table 4. Relative frequencies of types of seedlings produced from each population.

\begin{tabular}{llcccc}
\hline Seed & Pollen & \multicolumn{2}{c}{ Seedling type produced } & & Total no. seed \\
\cline { 2 - 4 } cultivar & Source & Nucellar & Zygotic & Both & germinated \\
\hline Smooth Flat Seville & Open & 129 & 103 & 45 & 277 \\
Yuma & Open & 131 & 54 & 3 & 188 \\
Cipo & Open $(\mathrm{F})^{\mathrm{z}}$ & 247 & 2 & 0 & 249 \\
& Open $(\mathrm{R})^{\mathrm{z}}$ & 70 & 1 & 0 & 71 \\
& trifoliata & 135 & 6 & 1 & 142 \\
Combined total & ichangensis & 61 & 6 & 9 & 76 \\
\end{tabular}

${ }^{\mathrm{z}} \mathrm{F}=$ Whitmore Foundation Farm, Leesburg, Fla.; R = Citrus Variety Collection, Univ. of California, Riverside.

Table 5. Logit equations for seedling type (excluding dead) where logit $(P)$ is for nucellar (Smooth Flat Seville and Yuma) or zygotic ('Cipo').

\begin{tabular}{llcc}
\hline $\begin{array}{l}\text { Seed } \\
\text { cultivar }\end{array}$ & $\begin{array}{c}\text { Pollen } \\
\text { source }\end{array}$ & $\begin{array}{c}\chi^{2} \text { for } \\
\text { model fit } \\
(P)\end{array}$ & $\begin{array}{c}\text { Logit } \\
\text { equations } \\
(P)^{\mathrm{z}}\end{array}$ \\
\hline $\begin{array}{llcl}\text { Smooth Flat Seville } \\
\text { Yuma }\end{array}$ & Open & 0.0003 & $-5.5896-0.0149(\mathrm{~W})+0.2344(\mathrm{~L})+1.0274(\mathrm{~T} 2)$ \\
Cipo & Open & 0.0030 & $0.8251+0.6876(\mathrm{~W} 1)-0.4980(\mathrm{~W} 2)$ \\
& Open $(\mathrm{F})^{\mathrm{z}}$ & --- & None \\
& Open $(\mathrm{R})^{\mathrm{z}}$ & --- & None \\
trifoliata & --- & None \\
ichangensis & 0.0030 & $4.6425+0.0502(\mathrm{~W})-1.0992(\mathrm{~T} 1)-1.6688(\mathrm{~T} 2)$
\end{tabular}

${ }^{\mathrm{z}} \mathrm{F}=$ Whitmore Foundation Farm, Leesburg, Fla.; $\mathrm{R}=$ Citrus Variety Collection, Univ. of California, Riverside.

inverse relationship of the two "width" measurements.

Stepwise logistic regression was used to select the most useful measurements in predicting seedling type for seed of 'Cipo'. In this case, the logit equation was used to predict the probability that the seed was ZB (not N, as was used for Smooth Flat Seville and Yuma). For a breeding parent like 'Cipo', zygotic seedlings are the desired product. The 'Cipo' $\mathrm{x} C$. ichangensis cross was the only population for which any seed characteristics were selected by the stepwise procedure for the logit equation. The inability to identify significant seed attributes for the other 'Cipo' populations probably resulted from the small number of $Z$ and $\mathrm{B}$ individuals in those populations (two in the open-pollinated 'Cipo' from Riverside, one in the open-pollinated 'Cipo' from Leesburg, and seven in the 'Cipo' $\mathrm{x} P$. trifoliata). For the 'Cipo' $\times C$. ichangensis cross, the percentage of seed in the entire population yielding zygotic seedlings (singly or intermixed with nucellar seedlings) was $19.7 \%$ ( 15 zygotic seedlings of 76 germinated seeds). Using the calculated logit equation to select seed, the percentage of seed yielding zygotic seedlings in the predicted zygotic seedling population was $25 \%$ at $P \geq 0.08$ (14 actual zygotic seedlings of 56 predicted zygotic seedlings). The percentage of zygotic seedlings increased gradually to $40.9 \%$ at $P>0.24$ (nine actual zygotic seedlings of 22 predicted zygotic seedlings). At a logit probability level of 0.50 , the percentage of zygotic seedlings was $57.1 \%$ (four actual zygotics of seven predicted 
zygotics). As the weight of a 'Cipo' $\mathrm{x} C$. ichangensis seed increased, the probability increased that the seed would yield a zygotic seedling; however, as the thickness (T1 and $\mathrm{T} 2$ ) of the seed increased, the probability decreased that the seed would yield a zygotic seedling.

The relationship between seed dimensions and seedling type differed among the three cultivars. However, for Smooth Flat Seville and 'Cipo', there appeared to be a similar positive correlation between seed weight and the likelihood of recovering a zygotic seedling: heavier seed were more likely to produce zygotic seedlings. For these same two cultivars, there also was a negative correlation between seed thickness (T1 and T2) and the likelihood of recovering a zygotic seedling: thinner seed were more likely to produce zygotic seedlings. Xiang and Roose (1988) did not examine Smooth Flat Seville or 'Cipo'; however, in that study, the smaller of the two categories of seed yielded a higher frequency of zygotic seedlings.

Measuring seed by the methods used in this study would be impractical for commercial sorting. However, devices could be constructed to rapidly separate seed using some of these seed dimensions. Sorting seed based on seed dimensions to increase the percentage of seed that yield only nucellar seedlings appears possible to a limited extent for Smooth Flat Seville and Yuma. However, the correlation between seed shape and recovery of nucellar seedlings did not appear strong enough to make the process worthwhile for commercial production of Smooth Flat Seville or Yuma liners in the nursery industry. The gains in purity would be too modest to compensate for the expense of sorting (even if some relatively efficient device was developed) and the substantial loss of actual nucellar seed that would be removed from the "sorted" population by error.

Most of the seed used in these tests were open-pollinated and could have had diverse pollen parentage (except those from controlled crosses) because of the close proximity of the seed trees to numerous other flowering cultivars. Data from 'Cipo' seed (Table 2) suggest it is possible that the pollen parent may have had an effect on seed shape (xenia). If this is the case, seed collected from Smooth Flat Seville (or other potential rootstock cultivars) that have been pollenized by only one pollen source (or selfed) might be sorted more effec- tively than the diversely pollenized seed.

The relative frequency of hybrid production from 'Cipo' seed appeared to vary by pollenizer cultivar. The frequency of hybrids from open-pollinated 'Cipo' seed was $<1 \%$ but was $5 \%$ when pollenized by $P$. trifoliata and $20 \%$ when pollenized by $C$. ichangensis. This effect has been reported previously for crosses of $P$. trifoliata onto Citrus jambhiri Lush. (Frost and Soost, 1968) and sweet orange (Hearn, 1977). The influence of pollen parent on the frequency of nucellar seedlings presents the possibility for reducing zygotics in Smooth Flat Seville seed (or seed of other rootstock cultivars) by controlling the proximity of other citrus cultivars to seed source trees.

Separation of 'Cipo' seed that will yield zygotic seedlings from those that will yield only nucellar seedlings appears possible, but it is probably impractical for normal breeding situations. When hybrids are rare from a particular seed parent, the breeder would generally be unwilling to sacrifice even a small proportion of hybrids for the sake of eliminating a modest proportion of nucellars. However, there are some situations when this process might prove useful - for example, producing a population of selfed zygotic seedlings for genetic studies. The geneticist might collect seed from a pure planting of the cultivar of interest. Large quantities of seed would be readily available and discarding some zygotic seed along with the nucellar seed would not be cause for concern. Sorting seed based on size and shape could be used to substantially increase the proportion of seeds that would yield hybrids. This procedure would reduce the number of seed to a manageable size for planting, subsequent seedling growth, and more detailed genetic analysis.

\section{Literature Cited}

Barrett, H.C. and A.M. Rhodes. 1976. A numerical taxonomic study of affinity relationships in cultivated Citrus and its close relatives. Systematic Bot. 1:105-136.

Bowman, K.D. 1994a. Inheritance of procumbent growth characteristics among hybrids of 'Cipo' sweet orange. HortScience 29:505. (Abstr.)

Bowman, K.D. 1994b. Cipo sweet orange and its unique growth habit. Fruit Var. J. 48:230-234.

Castle, W.S., R.R. Pelosi, C.O. Youtsey, F.G. Gmitter, Jr., R.F. Lee, C.A. Powell, and X. Hu. 1992. Rootstocks similar to sour orange for Florida citrus trees. Proc. Fla. State Hort. Soc. 105:56-60.
Chilembwe, E.H.C., W.S. Castle, and D.J.Cantliffe. 1992. Grading, hydrating, and osmotically priming seed of four citrus rootstocks to increase germination rate and seedling uniformity. J. Amer. Soc. Hort. Sci. 117:368-372.

Durham, R.E., P.C. Liou, F.G. Gmitter, Jr., and G.A. Moore. 1992. Linkage of restriction fragment length polymorphisms and isozymes in Citrus. Theor. Appl. Genet. 84:39-48.

Esen, A. and R.K. Soost. 1973. Relation of unexpected polyploids to diploid megagametophytes and embryo: Endosperm ploidy ratios in citrus. I. Congreso Mundial De Citricultura, MurciaValencia 2:53-63.

Frost, H.B. and R.K. Soost. 1968. Seed reproduction: Development of gametes and embryos, $\mathrm{p}$. 290-324. In: W. Reuther, L.D. Batchelor, and H.J. Webber (eds.). The citrus industry. vol. 2 (revised ed.). Univ. of California Press, Berkeley.

Grimm, G.R. and S.M. Garnsey. 1968. Foot rot and tristeza tolerance of smooth seville orange from two sources. Proc. Fla. State Hort. Soc. 81:8490.

Hearn, C.J. 1977. Recognition of zygotic seedlings in certain orange crosses by vegetative characters. Proc. Intl. Soc. Citricult. 2:611-614.

Hodgson, R.W. 1967. Horticultural varieties of citrus, p. 431-591. In: W. Reuther, H.J. Webber, and L.D. Batchelor (eds.). The citrus industry. vol. 1. Univ. of California Press, Berkeley.

Hutchison, D.J. 1985. Rootstock development screening and selection for disease tolerance and horticultural characteristics. Fruit Var. J. 39(3):21-25.

Hutchison, D.J., C.J. Hearn, and F.W. Bistline. 1992. The performance of 'Valencia' orange trees on 21 rootstocks in the Florida flatwoods. Proc. Fla. State Hort. Soc. 105:60-63.

Khan, I.A. and M.L. Roose. 1988. Frequency and characteristics of nucellar and zygotic seedlings in three cultivars of trifoliate orange. J. Amer. Soc. Hort. Sci. 113:105-110.

Parlevliet, J.E. and J.W. Cameron. 1959. Evidence on the inheritance of nucellar embryony in citrus. Proc. Amer. Soc. Hort. Sci. 74:252-260.

Soost, R.K., T.E. Williams, and A.M. Torres. 1980. Identification of nucellar and zygotic seedlings of citrus with leaf isozymes. HortScience 15:728729.

Starrantino, A. and G. Reforgiato-Recupero. 1981. Citrus hybrids obtained in vitro from $2 \mathrm{x}$ females $x 4 x$ males. Proc. Intl. Soc. Citricult. $1: 31-32$.

Vallejos, C.E. 1983. Enzyme staining activity, p. 469-516. In: S.D. Tanksley and T.J. Orton (eds.). Isozymes in plant genetics and breeding, part A. Elsevier, Amsterdam.

Xiang, C. and M.L. Roose. 1988. Frequency and characteristics of nucellar and zygotic seedlings in 12 citrus rootstocks. Sci. Hort. 37:47-59. 